\title{
Cultivo hidropônico de plântulas de sorgo sob estresse salino com sementes envelhecidas artificialmente e osmocondicionadas
}

\author{
Hydroponic growth of sorghum seedlings under salt stress with artificially aged and primed seeds
}

\author{
Alexandre Bosco de Oliveira ${ }^{I}$ Enéas Gomes Filho"I
}

RESUMO

Este trabalho teve por objetivo avaliar o crescimento inicial de plântulas de sorgo, provenientes de sementes submetidas e não ao envelhecimento $e$ ao osmocondicionamento, sob condições de estresse salino. $O$ delineamento experimental foi o inteiramente casualizado com quatro repetições, no esquema fatorial $2 \times 2 \times 3$, constando de 12 tratamentos: dois lotes de sementes (envelhecidas e não); dois tipos de sementes (osmocondicionadas e não) e três niveis de salinidade $(0,100$ e $200 \mathrm{mM}$ de $\mathrm{NaCl})$. O osmocondicionamento com polietilenoglicol 6000 ou priming de sementes não envelhecidas promoveu um aumento de $25 \%$ na sobrevivência das plântulas sob condições de alta salinidade (200mM de $\mathrm{NaCl})$, mas, quando essa técnica foi aplicada em sementes envelhecidas, ocorreram incrementos de 31,3 e 50\% na taxa de mortalidade de plântulas cultivadas na presença de $\mathrm{NaCl}$ a 100 e $200 \mathrm{mM}$. Quanto à manutenção do crescimento das plântulas, o osmocondicionamento proporcionou atenuação dos efeitos negativos da salinidade ( $\mathrm{NaCl}$ a $100 \mathrm{mM})$ naquelas oriundas de sementes envelhecidas, sendo tal fato confirmado por meio da manutenção da produção de biomassa vegetal.

Palavras-chave: Sorghum bicolor, produção de biomassa, envelhecimento acelerado, priming, $\mathrm{NaCl}$.

\section{ABSTRACT}

The aim of this research was the evaluate seedlings growth from primed and aged seeds of sorghum under ideal conditions and salt stress. The experiment was a completely randomized design with four replications, following a factorial arrangement of $2 \times 2 \times 3$, with eight treatments: two groups of seeds (aged or not), two types of seeds (primed or not) and three growth conditions $(0,100$ e $200 \mathrm{mM}$ of $\mathrm{NaCl})$. The osmoconditioning of no aged seeds promoted an increase of $25 \%$ in the seedling survival under conditions of high salinity ( $\mathrm{NaCl}$ at 200mM), but when this technique was applied in aged seeds caused $18.8 \%$ and $31.3 \%$ of increase in the mortality of the seedlings grown in the presence of $\mathrm{NaCl}$ at 100 and $200 \mathrm{mM}$, respectively. Regarding to the maintenance of seedling growth, the osmoconditioning provided mitigating the negative effects of salinity ( $\mathrm{NaCl}$ at $100 \mathrm{mM}$ ) for seedlings from aged seeds, and this fact is confirmed by the maintenance of plant biomass yield.

Key words: Sorghum bicolor, biomass yield, accelerated aging, priming, $\mathrm{NaCl}$.

\section{INTRODUÇÃO}

A utilização de sementes de alta qualidade é um pré-requisito para o estabelecimento rápido e uniforme das plântulas no campo com consequências no estande, na produtividade e na qualidade do produto colhido. A qualidade da semente é particularmente crítica quando são utilizados novos cultivares ou híbridos, pois, devido ao alto custo, há necessidade de melhores técnicas para se obter melhor emergência. Visando à melhoria na qualidade das sementes e rápido e uniforme estabelecimento de plântulas, diferentes tipos de tratamentos têm sido propostos, dentre eles, o condicionamento osmótico.

'Departamento de Fitotecnia, Universidade Estadual do Piauí (UESPI), Uruçuí, PI, Brasil.

"Departamento de Bioquímica e Biologia Molecular e Instituto Nacional de Ciência e Tecnologia em Salinidade (INCTSal), Universidade Federal do Ceará (UFC), CP 6039, 60455-970, Fortaleza, CE, Brasil. E-mail: egomesf@ufc.br. Autor para correspondência. 
Em geral, o uso do condicionamento osmótico proporciona elevação no vigor das sementes, bem como a taxa, sincronia e porcentagem de emergência das plântulas. Além disso, os resultados são superiores aos obtidos com sementes não tratadas de várias espécies, particularmente sob condições de estresse, como temperatura sub ou supra ótima (FOTI et al., 2002), déficit hídrico (FANTI \& PEREZ, 2003) ou salinidade (PATANÈ et al., 2009).

Nas regiões áridas e semi-áridas, o déficit hídrico e o excesso de sais no solo têm limitado a produção agrícola. Esses fatores afetam negativamente a germinação, o estande das plantas, o desenvolvimento vegetativo das culturas, a produtividade e, nos casos mais graves, causam a morte das plântulas (SILVA \& PRUSKI, 1997).

O estresse salino afeta virtualmente todos os aspectos da fisiologia e metabolismo das plantas. Os efeitos deletérios da salinidade no crescimento das plantas estão associados com a redução do potencial osmótico da solução do solo (estresse hídrico), distúrbios nutricionais, efeito específico de alguns íons (estresse iônico) ou uma combinação desses fatores (MUNNS, 2002).

O sorgo é reconhecido por sua tolerância moderada aos estresses hídrico e salino (AQUINO et al., 2007), podendo constituir-se em uma alternativa para cultivos sob tais condições. $\mathrm{O}$ uso do sorgo se justifica, também, por suas características bromatológicas que, à semelhança do milho, possibilitam fermentação adequada e armazenamento sob forma de silagem, pelos teores elevados de carboidratos solúveis e de proteína bruta em algumas variedades, além de suas características agronômicas que, entre outras, incluem elevada produtividade de biomassa (VON PINHO et al., 2006).

Esta pesquisa foi desenvolvida com o objetivo de avaliar o crescimento inicial de plântulas de sorgo sob cultivo hidropônico, provenientes de sementes submetidas e não ao envelhecimento e ao osmocondicionamento, sob condições ideais e de estresse salino.

\section{MATERIAL E MÉTODOS}

Foram utilizadas sementes de sorgo granífero [Sorghum bicolor (L.) Moench], cultivar IPA 1011, safra 2008, cedidas pela Empresa Pernambucana de Pesquisa Agropecuária (IPA), em Recife, PE, e armazenadas em frascos de vidro contendo sílica gel, à temperatura de $8^{\circ} \mathrm{C}$. Para aplicação dos tratamentos, o lote inicial de sementes foi dividido em dois sublotes: em um deles, as sementes foram submetidas ao estresse de temperatura $\left(43^{\circ} \mathrm{C}\right)$, sob umidade relativa do ar próxima de $100 \%$, por 72 horas, de acordo com a metodologia para envelhecimento artificial de sementes de sorgo, recomendada por MIRANDA et al. (2001); o outro sublote de sementes permaneceu sem nenhum tratamento (sementes não envelhecidas) e que serviu de controle. A germinação das sementes dos lotes considerados de alto e baixo vigor, isto é, de sementes não submetidas e submetidas ao envelhecimento artificial, respectivamente, foi de 90 e $65 \%$. Após esse procedimento, a metade das sementes de cada um desses sublotes foi submetida ao tratamento de condicionamento osmótico.

A metodologia e a concentração da solução de PEG-6000 para o condicionamento osmótico foram baseadas em recomendações de pesquisas anteriores com a germinação de sementes de sorgo osmocondicionadas (FOTI et al., 2002; PATANÈ et al., 2009; OLIVEIRA \& GOMES-FILHO, 2010). Durante o osmocondicionamento, as sementes foram colocadas em béqueres de $400 \mathrm{~mL}$ contendo $200 \mathrm{~mL}$ de solução de PEG-6000 a $250 \mathrm{~g} \mathrm{~L}^{-1}$, a qual correspondeu a um potencial osmótico de - $0,86 \mathrm{MPa}$ a $15^{\circ} \mathrm{C}$, que foi a temperatura em que as sementes foram deixadas por 48 horas de embebição nessa solução osmótica. O condicionamento osmótico foi conduzido em uma incubadora, sob escuro contínuo e aeração constante, a fim de garantir condições normais de respiração das sementes. Na parte inferior de cada béquer, foi fixada uma mangueira estreita, com pedra porosa anexada na ponta, a qual se manteve conectada a uma pequena bomba de aquário, responsável pela insuflação de ar na solução. Após o condicionamento, as sementes foram cuidadosamente lavadas; primeiro com água da torneira e depois com água destilada, sendo finalmente postas para secar em papel de filtro mata-borrão, por 72 horas, em ambiente de laboratório. Em seguida, as sementes foram desinfectadas em solução de hipoclorito de sódio a $1 \%$, por cinco minutos, e colocadas para germinar em germinador a $25^{\circ} \mathrm{C}$, entre folhas de papel mata borrão umedecidas com água desionizada ou soluções de $\mathrm{NaCl}$ a 100 e $200 \mathrm{mM}$ na proporção de 2,5 vezes a massa do substrato seco.

Dez dias após a semeadura, as plântulas mais uniformes de cada repetição foram transferidas para recipientes plásticos contendo $10 \mathrm{~L}$ de solução nutritiva de Hoagland diluída 1:2 (controle) ou contendo $\mathrm{NaCl}$ nas concentrações de 100 ou $200 \mathrm{mM}$ de $\mathrm{NaCl}$ (tratamentos de estresse). Foram cultivadas 12 plântulas por vaso, sendo as soluções nutritivas mantidas sob aeração constante e substituídas em intervalos de cinco dias. $\mathrm{O} \mathrm{pH}$ foi ajustado para 5,5, com $\mathrm{NaOH}$ a $0,1 \mathrm{M}$ ou $\mathrm{HCl}$ a $0,1 \mathrm{M}$. A quantidade de 
água transpirada pelas plantas foi reposta diariamente nos vasos, utilizando-se para isso água destilada.

Aos 14 dias sob cultivo hidropônico, isto é, no final do experimento (24 dias após a semeadura), calculou-se a porcentagem de plântulas normais, baseando-se nos critérios recomendados pelas Regras para Análise de Sementes - RAS (BRASIL, 2009). Em seguida, as plântulas foram coletadas, divididas em parte aérea e raízes e submetidas à secagem em estufa com circulação forçada de ar a $80^{\circ} \mathrm{C}$, até atingir peso constante. Posteriormente, esse material foi pesado em balança digital com precisão de duas casas decimais (gramas) para obtenção da massa da matéria seca da parte aérea e das raízes. A partir da soma e divisão dos valores dessas variáveis, obteve-se a massa da matéria seca total e a razão entre massa da matéria seca da parte aérea e das raízes, respectivamente.

O delineamento experimental adotado foi o inteiramente casualizado, com quatro repetições de 12 plântulas, em esquema fatorial $2 \times 2 \times 3$ para as variáveis de crescimento, tendo, como tratamentos, a combinação de dois sublotes de sementes com diferentes qualidades fisiológicas (envelhecidas e não envelhecidas), dois grupos de sementes distintas (submetidas e não ao osmocondicionamento) e três níveis de estresse salino (0, 100 e 200mM de $\mathrm{NaCl})$. A análise de variância e a comparação de médias foram realizadas através do teste $\mathrm{F}$ e Tukey, respectivamente, ambos ao nível de 5\% de probabilidade (BANZATTO \& KRONKA, 2006).

\section{RESULTADOS E DISCUSSÃO}

Não houve diferença significativa no percentual de sobrevivência das plântulas provenientes de sementes de maior vigor (não envelhecidas artificialmente), submetidas aos tratamentos com 0 e $100 \mathrm{mM}$ de $\mathrm{NaCl}$ no meio de cultivo (Figura 1A). A salinidade excessiva, neste experimento, representada pelo $\mathrm{NaCl}$ em solução nutritiva a $200 \mathrm{mM}$, promoveu a morte de $50 \%$ das plântulas oriundas de sementes que não foram expostas aos procedimentos de envelhecimento e condicionamento osmótico, revelando que esse nível de estresse promoveu decréscimos significativos na sobrevivência das plântulas de sorgo. Esses efeitos deletérios do $\mathrm{NaCl}$, entretanto, foram atenuados pelo condicionamento osmótico de sementes, uma vez que aquelas submetidas a esse tratamento mantiveram a porcentagem de sobrevivência média em $75 \%$, ou seja, com níveis que não diferiram dos tratamentos com menores teores desse sal no meio de cultivo $(87,5 \%)$. Portanto, os resultados obtidos corroboram a afirmação de JELLER (2002), a qual dissertou que diversos benefícios têm sido relatados com o emprego da técnica do condicionamento osmótico, dentre eles, o aumento da possibilidade de se obter uma maior porcentagem de germinação, particularmente sob condições adversas, como baixa disponibilidade hídrica, níveis elevados de salinidade e temperaturas sub e supraótimas.

Nas plântulas oriundas de sementes envelhecidas artificialmente, constataram-se reduções

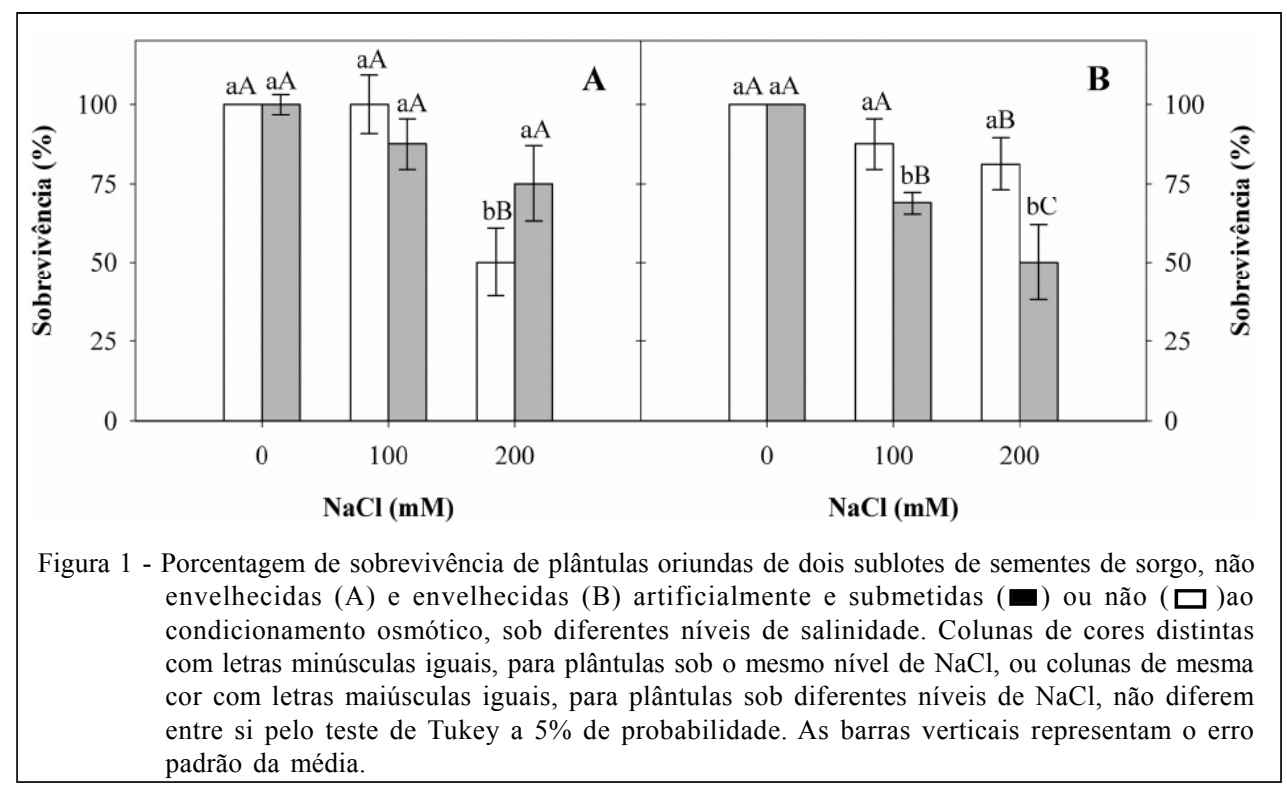

Ciência Rural, v.41, n.1, jan, 2011. 
significativas na sobrevivência quando foram submetidas ao estresse salino com $\mathrm{NaCl}$ a 100 e $200 \mathrm{mM}$, com maiores decréscimos em plântulas oriundas de sementes osmocondicionadas, nas quais houve efeito significativo ao nível de 100 e $200 \mathrm{mM}$, com reduções de 31,3 e $50 \%$, respectivamente (Figura 1B). Portanto, nesse caso, foram constatados efeitos adversos do osmocondicionamento sobre a sobrevivência de plântulas em condições de salinidade.

A salinidade afetou negativamente a massa seca da parte aérea $(P \leq 0,05)$, com efeitos mais prejudiciais em plântulas geradas a partir do grupo de sementes de menor vigor, para as quais se observaram reduções significativamente superiores, em função do incremento nos teores de sal do meio de cultivo, sendo de 69 e $80,2 \%$ em sementes não condicionadas e de 54,9 e $79,7 \%$ em sementes submetidas ao osmocondicionamento, ambos a 100 e $200 \mathrm{mM} \mathrm{de} \mathrm{NaCl}$, respectivamente (Figura 2A e 2B). Nas plântulas provenientes de sementes de maior vigor, não se detectou diferença significativa $(\mathrm{P} \geq 0,05)$ entre os dois níveis de $\mathrm{NaCl}(100$ e $200 \mathrm{mM})$ em que elas foram expostas, com valores na faixa de 19,8 a $27,9 \mathrm{mg}$ planta1. Cabe ressaltar que, nas sementes envelhecidas artificialmente, o condicionamento foi responsável pelo incremento de aproximadamente $27 \%$ na produção de massa seca da parte aérea das plântulas desse grupo, quando cultivadas sob $100 \mathrm{mM}$ de $\mathrm{NaCl}$. De forma semelhante ao que foi aqui observado, melhorias no desempenho de plântulas cultivadas sob estresses abióticos foram relatadas na literatura como respostas diretas do condicionamento de sementes. FANTI \& PEREZ (2003) relataram que o condicionamento osmótico aumentou o limite máximo de tolerância ao estresse hídrico; PEREIRA et al. (2009) constataram que o tratamento das sementes de cenoura com soluções de PEG-6000 aumentou a emergência das plântulas no campo e o desempenho sob temperaturas sub e supra-ótima; PATANÈ et al. (2009) verificaram que o osmocondicionamento de sementes de sorgo sacarino atenuou os efeitos deletérios, provocados pelos estresses salino e térmico durante a germinação e crescimento da radícula.

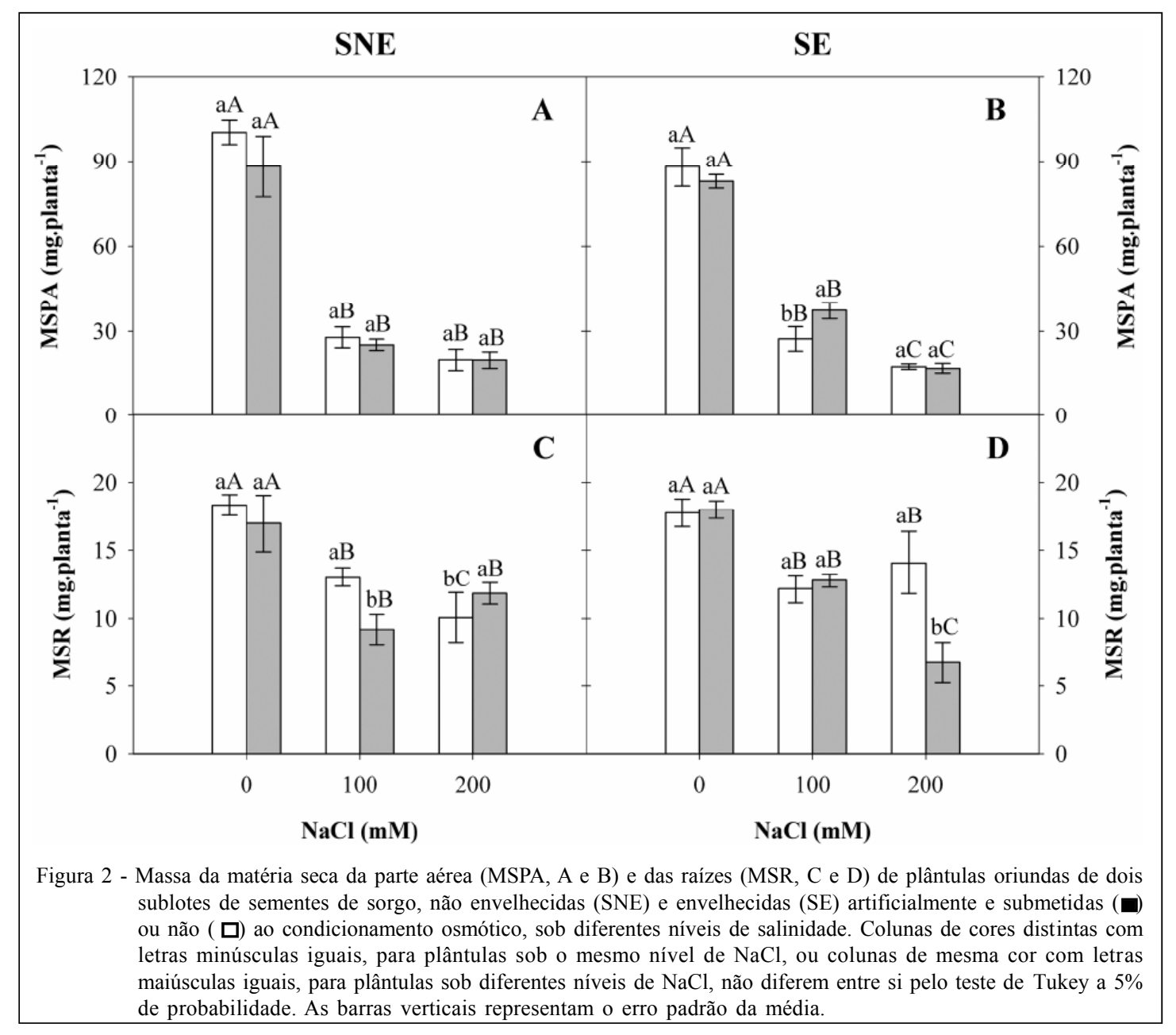

Ciência Rural, v.41, n.1, jan, 2011. 
De acordo com os resultados obtidos para massa seca da parte aérea em plântulas estressadas oriundas de sementes envelhecidas, acredita-se que esses efeitos sejam resultantes de um adiantamento metabólico sofrido pelas sementes osmocondicionadas. Esse adiantamento leva a um incremento na quantidade de macromoléculas sintetizadas, como ácidos nucléicos e proteínas, envolvendo a ativação ou síntese de novo de enzimas-chave envolvidas no processo de germinação (TRIGO et al., 2000) e até mesmo mecanismos de reparo das membranas com algum grau de desestruturação (FUJIKURA \& KARSSEN, 1992).

Os valores médios de massa seca das raízes variaram em função dos diferentes fatores avaliados, bem como houve interação significativa entre esses fatores $(\mathrm{P} \leq 0,05)$. Foram observados maiores decréscimos em sementes não envelhecidas e não condicionadas (Figura 2C), com reduções de 28,9 e $45,1 \%$, bem como em sementes envelhecidas que foram expostas ao osmocondicionamento, para os quais houve reduções na produção de massa seca das raízes em torno de 29,1 e $62,5 \%$, ambas a 100 e $200 \mathrm{mM}$, respectivamente (Figura 2D). Pode-se acrescentar que, em todos os tratamentos avaliados nessa pesquisa, a massa da matéria seca das raízes foi menos afetada pelo estresse salino do que a da parte aérea, com reduções de 28,9 a 62,5\% para a primeira e de 54,9 a 80,2 para esta última variável. De acordo com MUNNS (2002), apesar de as raízes estarem diretamente expostas ao agente responsável pelo estresse, elas são menos vulneráveis aos sais do que a parte aérea. A maior redução do crescimento da parte aérea em relação às raízes tem sido observada também em outros trabalhos na literatura com plantas de sorgo, sugerindo que elas se adaptam melhor às condições de salinidade, provavelmente, devido ao ajustamento osmótico mais rápido deste órgão (AQUINO et al., 2007).

O condicionamento osmótico de sementes de menor vigor promoveu a atenuação do estresse salino em plântulas sob salinidade intermediária $(100 \mathrm{mM})$, nas quais se observaram valores de massa seca total $25,9 \%$ superiores àquelas oriundas de sementes não condicionadas (Figura 3B). Tais resultados confirmam que o condicionamento osmótico

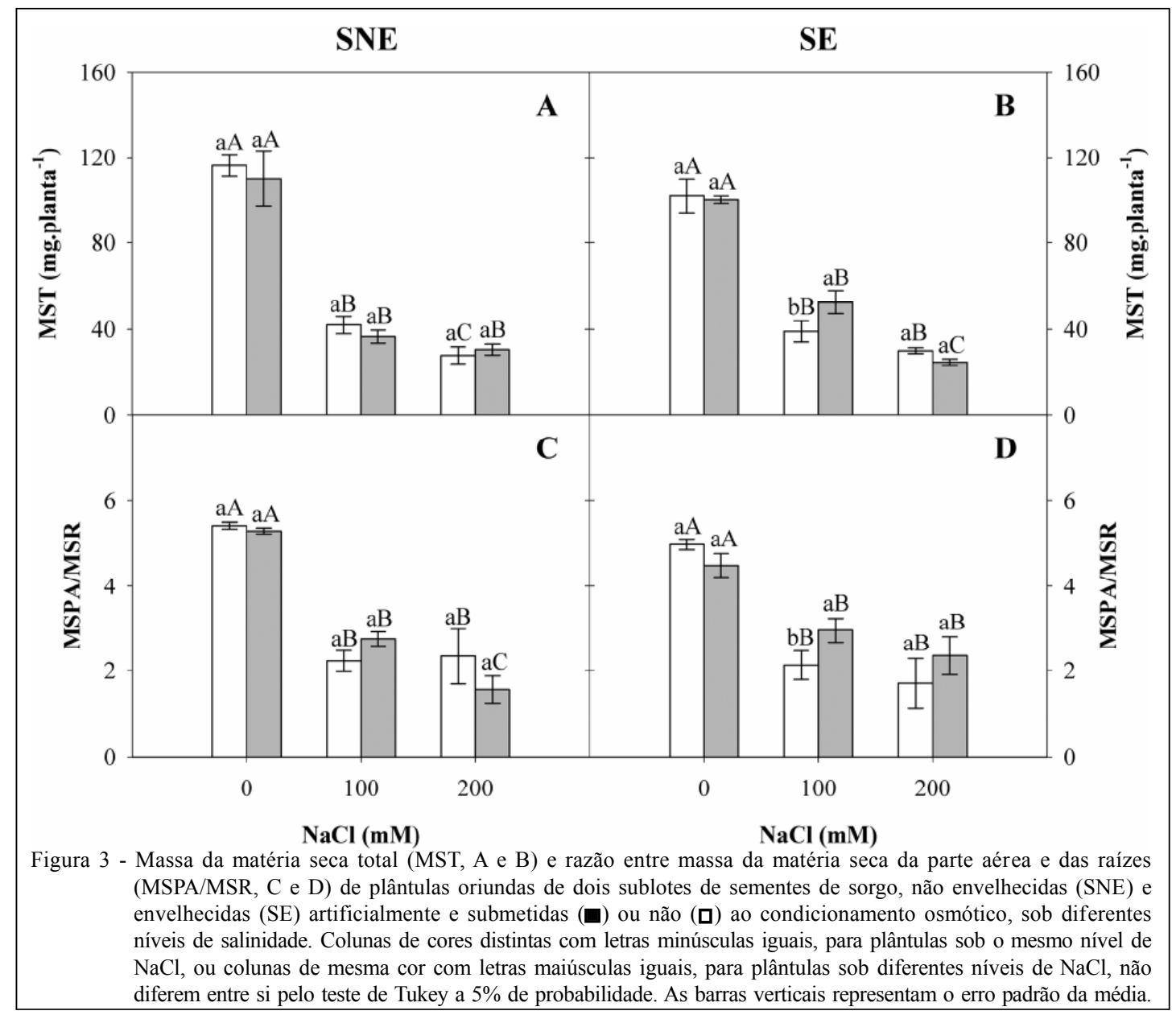

Ciência Rural, v.41, n.1, jan, 2011. 
foi eficiente em promover a adaptação das plântulas de sorgo ao estresse salino. De maneira semelhante ao que foi constatado neste experimento, HALPININGHAM \& SUNDSTROM (1992) relataram, em sua pesquisa com plântulas provenientes de sementes condicionadas de pimentão, que o osmocondicionamento aumentou o desenvolvimento delas, especialmente quanto à produção de massa seca do hipocótilo, a qual expressou um acréscimo em torno de $45 \%$ em função do osmocondicionamento.

Para os dados de massa seca total, constatou-se comportamento similar ao observado para a massa seca da parte aérea, indicando que a produção de biomassa da parte aérea exerceu influência significativa sobre a produção de biomassa total da planta. Isso significa dizer que os maiores valores obtidos em plântulas provenientes de sementes envelhecidas e osmocondicionadas, que foram cultivadas em solução nutritiva com $100 \mathrm{mM}$ de $\mathrm{NaCl}$ $\left(52,6 \mathrm{mg} \mathrm{planta}^{-1}\right)$, representando um incremento de $25,9 \%$ em relação às não condicionadas, possivelmente ocorreram devido aos maiores valores de massa seca da parte aérea, observados nesse tratamento $(37,4 \mathrm{mg}$ planta $^{-1}$ ), que obtiveram um acréscimo de $27 \%$ quando comparadas àquelas oriundas de sementes não sujeitas ao condicionamento osmótico (Figura 2B e 3B). Esses resultados podem estar relacionados com o relato de MARCELIS \& VAN HOOIJDONK (1999), os quais, trabalhando com estresse salino em Raphanus sativus, observaram que $80 \%$ da redução da produção de biomassa da planta foi, provavelmente, resultado do efeito negativo da salinidade sobre o crescimento da folha, reduzindo a área superficial disponível para incidência da energia luminosa, utilizada no processo de fotossíntese.

A salinidade provocou reduções significativas na razão entre massa seca da parte aérea e das raízes (Figura 3C e 3D), destacando-se as plântulas oriundas de sementes não envelhecidas e osmocondicionadas, com decréscimos nos valores dessa variável de maneira diretamente proporcional ao incremento nos níveis de $\mathrm{NaCl}$ da solução de cultivo, isto é, 48 e 70,5\% de redução na variável em questão a 100 e $200 \mathrm{mM}$ de $\mathrm{NaCl}$, respectivamente. Nos demais tratamentos, não houve diferença significativa para essa variável nas plântulas cultivadas na presença de diferentes concentrações desse sal (100 e 200mM de $\mathrm{NaCl}$ ), com valores numéricos para essa relação variando entre 1,7 e 2,3. Tendo em vista que houve maiores efeitos da salinidade sobre a produção de biomassa da parte aérea do que a das raízes, pode-se deduzir que a razão entre massa seca da parte aérea e das raízes de plântulas de sorgo sofreu relevante influência da produção de biomassa na parte aérea, uma vez que essa variável foi mais afetada pelos tratamentos avaliados do que a massa seca das raízes.

A menor redução do crescimento das raízes pode resultar na ampliação da área de absorção de nutrientes e água do solo, de forma a minimizar os efeitos prejudiciais do sal (FERREIRA et al., 2001). A salinidade afeta a produção de biomassa e altera a partição de fotoassimilados entre as diferentes partes das plantas, sendo essas respostas decorrentes dos efeitos osmóticos, tóxicos e nutricionais (MUNNS, 2002; AQUINO et al., 2007). De acordo com PARANYCHIANAKIS \& CHARTZOULAKIS (2005), os efeitos negativos da salinidade sobre o crescimento das plantas estão associados a sua interferência nos processos de assimilação líquida por unidade de área foliar, de translocação de carboidratos para tecidos drenos e no desvio de fontes de energia para outros processos, tais como: ajustamento osmótico, síntese de solutos compatíveis, reparo de danos causados pela salinidade e manutenção dos processos metabólicos básicos.

\section{CONCLUSÃO}

O condicionamento osmótico das sementes não envelhecidas promoveu o aumento da sobrevivência das plântulas sob condições de estresse salino a $200 \mathrm{mM}$ de $\mathrm{NaCl}$, mas, quando essa técnica foi aplicada em sementes envelhecidas, houve aumento na taxa de mortalidade de plântulas sob salinidade.

No que diz respeito à manutenção do crescimento das plântulas, o osmocondicionamento proporcionou atenuação dos efeitos negativos da salinidade $(\mathrm{NaCl}$ a $100 \mathrm{mM})$ naquelas oriundas de sementes envelhecidas, sendo tal fato confirmado por meio da manutenção da produção de biomassa vegetal.

\section{REFERÊNCIAS}

AQUINO, A.J.S. et al. Crescimento, partição de matéria seca e retenção de $\mathrm{Na}^{+}, \mathrm{K}^{+}$e $\mathrm{Cl}^{-}$em dois genótipos de sorgo irrigados com águas salinas. Revista Brasileira de Ciência do Solo, Viçosa, v.31, n.5, p.961-871, 2007. Disponível em: <http:// www.scielo.br/scielo.php? script $=$ sci_arttext\&pid $=$ S0100$06832007000500013 \& \operatorname{lng}=\mathrm{en} \& \mathrm{nrm}=\mathrm{iso}>$. Acesso em: 12 ago. 2010. doi: $10.1590 / \mathrm{S} 0100-06832007000500013$.

BANZATTO, D.A.; KRONKA, S.N. Experimentação agrícola. 4.ed. Jaboticabal: FUNEP, 2006. 237p.

BRASIL. Ministério da Agricultura, Pecuária e Abastecimento. Secretaria de Defesa Agropecuária. Regras para análise de sementes. Brasília: MAPA/ACS, 2009. 399p.

FANTI, S.C.; PEREZ, S.C.J.G.A. Efeito do estresse hídrico e envelhecimento precoce na viabilidade de sementes 
osmocondicionadas de paineira (Chorisia speciosa). Pesquisa Agropecuária Brasileira, Brasília, v.38, n.4, p.537-543, 2003. Disponível em: <http://www.scielo.br/ s cie lo.php? s cript $=$ s ci_art text \& pid $=\mathrm{S} 0100-$ $204 X 2003000400013 \& \operatorname{lng}=\mathrm{en} \& \mathrm{nrm}=\mathrm{iso}>$. Acesso em: 23 nov. 2009. doi: 10.1590/S0100-204X2003000400013.

FERREIRA, R.G. et al. Distribuição da matéria seca e composição química das raízes, caule e folhas de goiabeira submetida a estresse salino. Pesquisa Agropecuária Brasileira, Brasília, v.36, n.1, p.79-88, 2001. Disponível em: <http://www.scielo.br/ s c i e lo.php? s cript=s ci_arttext \& pid = S $0100-$ 204X2001000100010\&lng=en\&nrm=iso>. Acesso em: 13 jul. 2009. doi: 10.1590/S0100-204X2001000100010.

FOTI, S. et al. Effect of osmoconditioning upon seed germination of sorghum (Sorghum bicolor (L.) Moench) under low temperatures. Seed Science and Technology, Zürich, v. 30, p.521-533, 2002 .

FUJIKURA, Y.; KARSSEN, C.M. Effects of controlled deterioration and osmopriming on protein synthesis of cauliflower seeds during early germination. Seed Science Research, Wallingford, v.2, p.23-31, 1992. Disponível em: $<$ http://dx.doi.org/10.1017/S0960258500001070>. Acesso em: 19 set. 2009 . doi: $10.1017 / \mathrm{S} 0960258500001070$.

HALPIN-INGHAM, B.; SUNDSTROM, F.J. Pepper seed water content, germination response and respiration following priming treatments. Seed Science and Tecnology, Zürich, v.20, p.589-596, 1992.

JELLER, H. Pré-condicionamento em sementes de Cassia excelsa Schrad. 2002. 81f. Tese (Doutorado em Ecologia e Recursos Naturais) - Universidade Federal de São Carlos, SP

MARCELIS, L.F.M.; VAN HOOIJDONK, J. Effect of salinity on growth, water use and nutrient use in radish (Raphanus sativus L.). Plant and Soil, Amsterdam, v.215, p.57-64, 1999. Disponível em: <http://dx.doi.org/10.1023/A:1004742713538>. Acesso em: 19 set. 2009. doi: 10.1023/A:1004742713538.

MIRANDA, D.M. et al. Avaliação do potencial fisiológico de sementes de sorgo pelo teste de envelhecimento acelerado. Revista Brasileira de Sementes, Pelotas v.23, n.1, p.226231, 2001.
MUNNS, R. Comparative physiology of salt and water stress. Plant, Cell and Environment, Oxford, v.25, p.239-250, 2002. Disponível em: <http://dx.doi.org/10.1046/j.00168025.2001.00808.x>. Acesso em: 25 jan. 2010. doi: 10.1046/ j.0016-8025.2001.00808.x.

OLIVEIRA, A.B.; GOMES-FILHO, E. Efeito do condicionamento osmótico na germinação e vigor de sementes de sorgo com diferentes qualidades fisiológicas. Revista Brasileira de Sementes, Londrina, v.32, n.3, p.25-34, set. 2010. Disponível em 〈http:// www.scielo.br/scielo.php?script=sci arttext\&pid=S010131222010000300003\&lng=pt\&nrm=iso>. Acesso em: 23 set. 2010. doi: 10.1590/S0101-31222010000300003.

PARANYCHIANAKIS, N.V.; CHARTZOULAKIS, K.S. Irrigation of Mediterranean crops with saline water: from physiology to management practices. Agriculture, Ecosystems and Environment, Zürich, v.106, p.171-187, 2005. Disponível em: <http://dx.doi.org/10.1016/j.agee.2004.10.006>. Acesso em: 11 maio, 2009. doi: 10.1016/j.agee.2004.10.006.

PATANE, C. et al. Germination and radicle growth in unprimed and primed seeds of sweet sorghum as affected by reduced water potential in $\mathrm{NaCl}$ at different temperatures. Industrial Crops and Products, Whashington DC, v.30, n.1, p.1-8, 2009. Disponível em: <http:// dx.doi.org/10.1016/j.indcrop.2008.12.005>. Acesso em: 22 jul. 2009. doi:10.1016/j.indcrop.2008.12.005

PEREIRA, M.D. et al. Primed carrot seeds performance under water and temperature stress. Scientia Agricola, Piracicaba, v.66, n.2, p.174-179, 2009. Disponível em: <http:// www.scielo.br/scielo.php?script $=$ sci arttext\&pid $=\mathrm{S} 0103$ $90162009000200005 \& \operatorname{lng}=$ en\&nrm=iso $>$. Acesso em: $27 \mathrm{mar}$. 2010. doi: 10.1590/S0103-90162009000200005.

SILVA, D.; PRUSKI, F.F. Recursos hídricos e desenvolvimento sustentável da agricultura. Brasília: MMA/SBH/ABEAS, 1997. 252p.

TRIGO, M.F.O.O. et al. Alterações isoenzimáticas em sementes de cebola sob condicionamento osmótico. Revista Científica Rural, Bagé, v.5, n.1, p.170-183, 2000.

VON PINHO, R.G. et al. Influência da altura de corte das plantas nas características agronômicas e valor nutritivo das silagens de milho e de diferentes tipos de sorgo. Revista Brasileira de Milho e Sorgo, Sete Lagoas, v.5, n.2, p.266279, 2006. Disponível em: < http://rbms.cnpms.embrapa.br/ index.php/ojs/article/view/189>. Acesso em: 03 out. 2008. 